\title{
Interactive digital documents to promote active learning of undergraduate mathematics
}

\author{
Sandra Gaspar Martins ${ }^{1}$ and Vitor Duarte Teodoro ${ }^{2}$ \\ ${ }^{1}$ Instituto Superior de Engenharia de Lisboa, Instituto Politécnico de Lisboa, Lisboa, Portugal \\ 2 Faculdade de Ciências e Tecnologia, Universidade Nova de Lisboa, Almada, Portugal \\ For correspondence: sandra.martins@adm.isel.pt
}

\begin{abstract}
The Interactive Digital Documents (IDDs) are a set of materials designed to support the teaching/learning of Mathematical Analysis/Calculus for Engineering students. They are interactive and promote active participation of students in the teaching/learning by making students choose the options that make sense through ComboBoxes and CheckBoxes, and answer questions through TextFields. They are customizable and are the single document that the students need for the course either in the classroom or in study moments: it contents the slides, the support book, the notebook, the exercises list, etc. The DDIs promote student-centred, collaborative and active learning in which the student evolves at his own pace. They are complemented with the use of software and Moodle quizzes. The approach to concepts: emphasizes mathematics applications; is made starting from the real/concrete approach to the abstract viewpoint; to introduce a concept the focus goes only to that concept, it is not mixed with others; explores multiple representations of concepts, not only the analytical but also the numerical, graphical and verbal ones. The exercises are presented having in mind the proximal development zone of students. The DDIs were tested during a semester in an experimental class to which students bring their own laptop everyday. Their evaluation by the students was strongly positive.
\end{abstract}

Keywords: Interactive, Digital, Documents, Active Learning, Undergraduate Mathematics, LaTeX.

\section{Introduction}

The problem of high failure rates at Mathematics in early years of graduations appears in many countries (Anderson and Loftsgaarden, 1987; Artigue, 2011; Caprotti et al, 2007; Machado, 2006; Tall, 1993; Zerr, 2010). Technology development allows to take advantage of computer to deepen students learning (Blackwell et al, 2007; Kaput, 1994; NCTM, 2000; Teodoro, 2002).

According to Chickering and Gameson (1987) to achieve active learning students must do "more than just listen: they must read, write, discuss, or be engaged in solving problems", students must be engaged in "higher-order thinking tasks as analysis, synthesis, and evaluation". Active learning is used, with success, in several approaches with different kinds of students; sometimes in top universities other times in common universities. Several projects are examples of it: SCALE-UP (Beichner, 2008) in North Carolina State University, TEAL (Dori and Belcher, 2004) in Massachusetts Institute of Technology (MIT), Peer Instruction (Crouch and Mazur, 2001) in Harvard University.

To take advantage of the computer to get deepen understanding of Mathematics by promoting Active Learning we, the researchers, created the Interactive Digital Documents (IDDs), a collection of digital documents that aims to provide support for students to learn Calculus 1/Mathematical Analysis 1 (C1) in theoretical-practical classes. The IDDs are all the material that the student needs for the course: the slides, the support book (with theory and exercises), the "notebook " where students solve the exercises and take their notes, the exercises list, etc.

The IDDs are interactive, not static documents from which the student gets information as in a traditional PDF, they drive students to answer questions, to complete the settings, to select the properties that make sense, to choose the meaningful options, etc. In this sense the IDDs encourage 
active learning; promote student centred teaching; allows the student to proceed at his own rhythm. Students learn autonomously since the IDDs take into account the zone of proximal development and thus, with a small support, the student progress on his own.

These documents suggest the use of software of different types; propose links to external sites that may be a complement to the study and have links to applets that help clarify concepts. The IDDs give emphasis to applications of mathematics, use multiple representations of concepts and suggest the creation of concept maps by students. They are also complemented with tests on Moodle that give immediate feedback of student's level of understanding.

\section{Interactivity}

To create the documents was used LaTeX and the package eForms that is part of AcroTeX (http://www.acrotex.net/) to get form fields like Combo Boxes, Check Boxes, Text Fields, etc. LaTeX was chosen because it allows to write math symbols with easiness, as well as interaction with simplicity; besides that, it's free and generates PDF documents which all students can read and add comments to.

The final product is an interactive PDF file. Combo Boxes are used to give the possibility to choose one between multiple options, to complete a sentence, or to choose a correct result. Students may write an answer, to a question, in a Text Field. Students are also able, in any part of any page, to add comments (written or audio) and write on it. Each student personalise his document according to his work, as he would do with a workbook on paper.

The Combo Boxes allow students to choose the meaningful option when a definition, a theorem, an example, a property or an exercise is presented (see Figure 1). The students must perform the action of choosing the correct option instead of being spectators receiving the properties that are being presented to them in its final form.

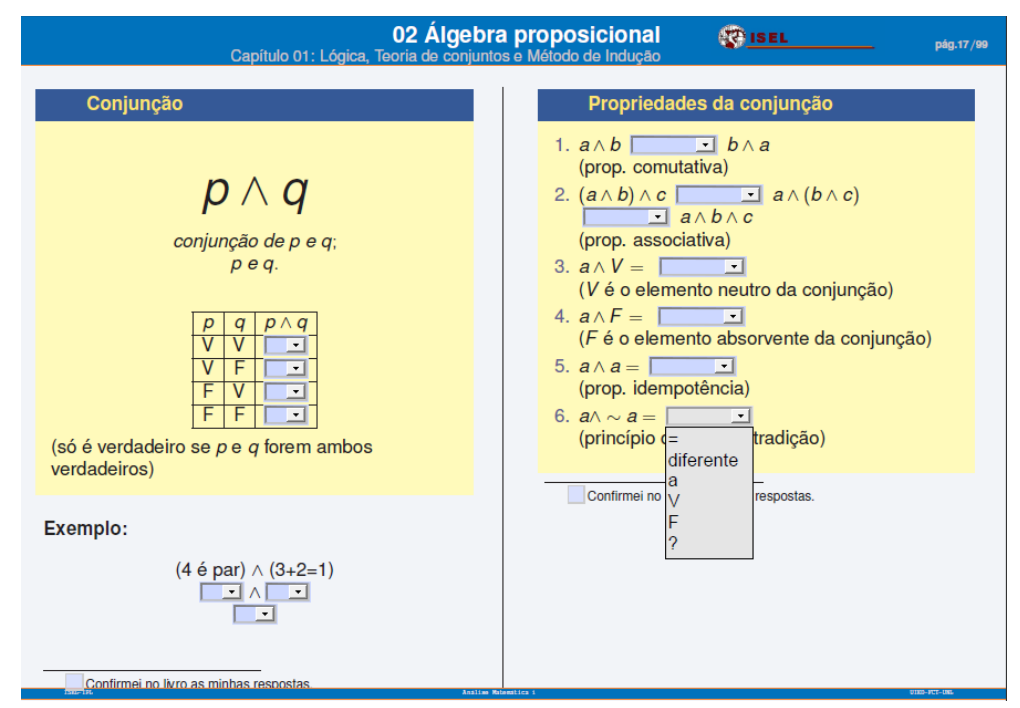

Figure 1. Using Combo Boxes to explore the concept of conjunction.

The Check Boxes allow the choice of one or more items among several items. The fundamental difference to Combo Boxes is that all possibilities are always visible and is possible to choose more than one item.

Both, Combo Boxes and Check Boxes, allow the students to choose an answer but do not give feedback about the correctness of the choice. It is possible, and easy to implement, to make that the students get immediate feedback thought the Internet. But it was not implemented in the IDDs since this could lead students not to think about the answer but simply try all chances until they get the correct answer, and also because all questions were corrected in lessons so, after a time of reflection, 
the students get the correct answers. This kind of feedback would be interesting to give the solutions to the exercises that are to be done out of class, feature that will be implement in a future work.

The Text Fields allow an open response from the student (see Figure 2).

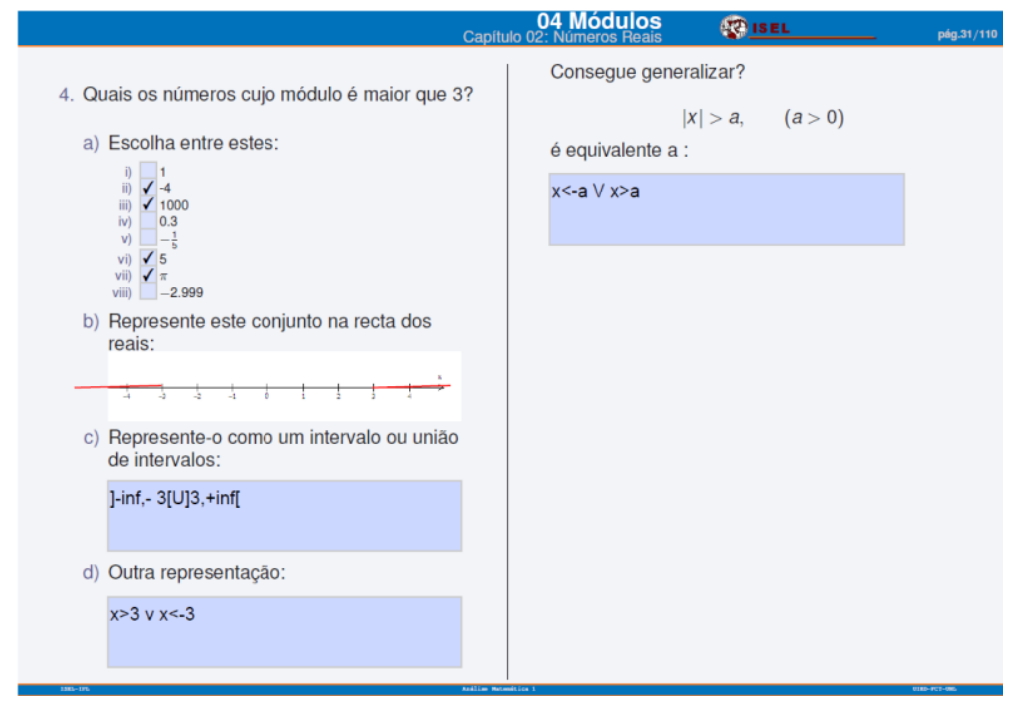

Figure 2. Using Check Boxes and Text Fields to explore the concept of absolute value.

Another form of interactivity is provided by the fact of being a PDF file. The Adobe Reader (which is free) allows, in any part of any page, to highlight text; to write a comment; to make arrows, squares or other forms; to write in it using a Pencil Tool; to capture a snapshot and stamp it into another place; to capture voice; etc. Each student will then personalize his document according to his work, as shown in Figure 3.

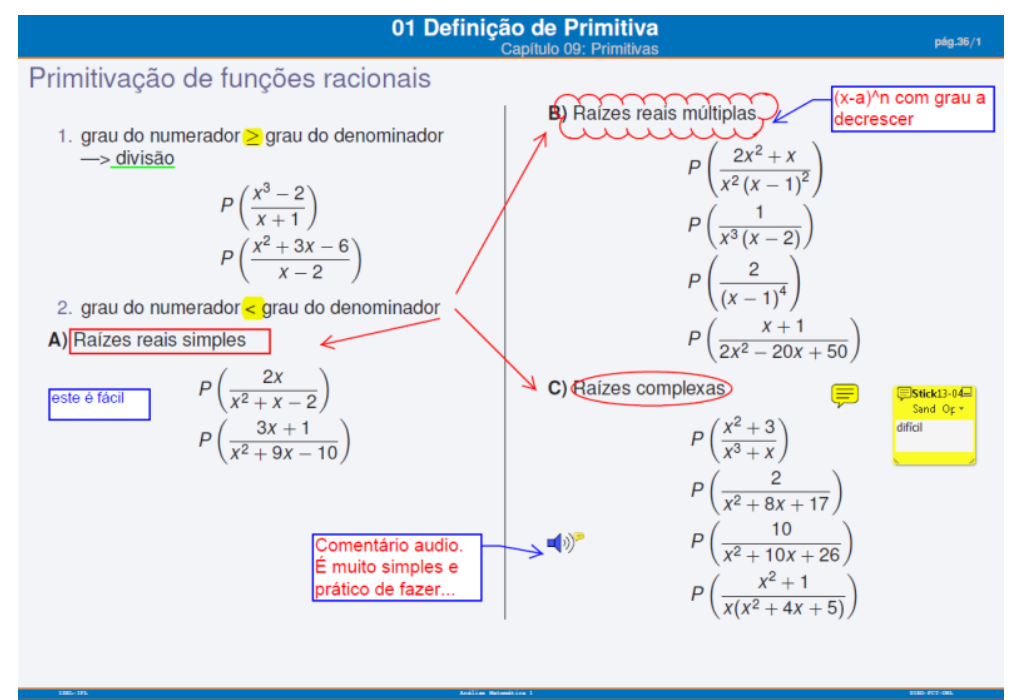

Figure 3. Example of a page personalized using the tools of Adobe Reader.

\section{Students' attitude fostered by the IDDs}

Since the IDDs are interactive, they can foster active learning. Students are encouraged to work on documents, instead of just passively receiving information - they are focused choosing the meaningful options and working at their own pace.

Active Learning. These documents promote active learning since they are not static and not only do they "tell" students about what the concepts are and how to solve the exercises, but they also take the students to distinguish what does and does not make sense for that concept, to build (in a guided and 
supported way) their own knowledge, to seek for solutions to the exercise rather than following some procedures without understanding the reason to do that. Figures 1,2 and 3 are illustrative of how the IDDs promote active learning. Of how they support a student-centred learning, where students learn by themselves, independently, at their own pace, with the support of the professor and colleagues whenever necessary.

Learning at Each One's Pace. Each group of exercises begins with simple exercises and ends up with more complex ones. Each student solves those exercises at his own pace, while the students who have more easiness advance up to the latest and face greater difficulties, those who find out more difficulty overcome with tranquillity each difficulty faced, gaining thereby self-confidence and being conscious that are "building up" their own knowledge "layer by layer" (see Figure 4).

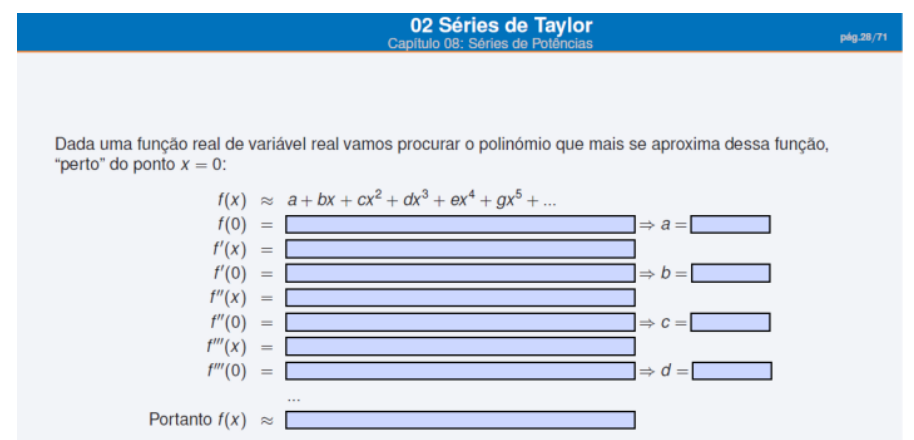

Figure 4. Construction of the Taylor polynomial by the student.

\section{Conceptual approach}

The presentation of concepts follows the following rules. Each one starts with a problem (an application of the concept to solve a real problem) to motivate the students and make it more concrete (more tangible by most students), then follows its generalization and consequent abstraction. Next, the exercises begin from the simpler until the most difficult ones, having in mind the Proximal Development Zone to allow the student to make the exercises alone (or with small support from the colleagues or the teacher); the exercises (particularly the initial ones) focus on each objective at a time. Whenever it makes sense, multiple representations of the concepts are used (not only the analytical view but also the graphical, numerical and verbal forms). In the end of a chapter, the students are required to make a concept map "to organize in their mind" the concepts and the relations between them: to make the "big picture" of the chapter.

Application Problems. The IDDs emphasize the application of concepts to real cases and preferably to cases usable by engineers or in day-by-day life. The purpose of including many exercises of applications is to motivate students to understand the concepts; to make students understand the importance of the use of mathematics in the development of engineering; to solve problems in dayby-day life; and test students' ability to find relevant data in a given context and apply it to produce knowledge. Another important reason for the introduction of these exercises is that, generally, they allow the development of high-level objectives of Bloom's taxonomy like: apply, analyse, evaluate and create. For example, the problem in Figure 5 has an abstract formulation which is "find the smallest area of a cylinder with a volume of $1000 \mathrm{v} . u$.". In the IDD, the wording in the form of real-life problem was consciously preferred. 


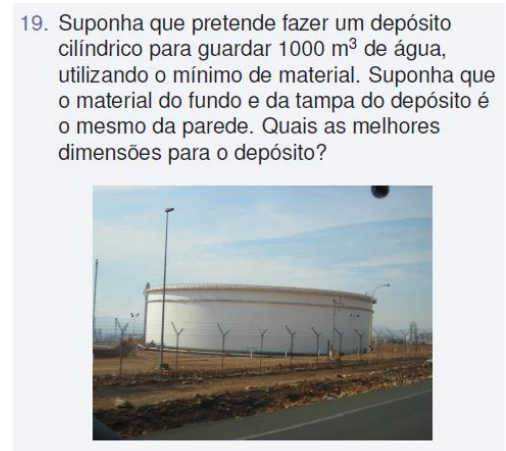

Figure 5. Problem about determination of the best dimensions of a water tank.

Concrete-to-Abstract approach to concepts. The IDDs use a concrete-to-abstract approach to concepts in opposition to the traditional calculus approach of abstract-to-concrete. Whenever it makes sense, concepts are introduced with real world problems or an example and then arrive to its generalized abstract form. This is made to motivate the learning and to give a concrete approach that facilitates understanding. For example, to address the definition of convergence of a series was introduced a concretization of Zenon's Paradox: when you throw an arrow at a target one meter away, there is a moment when the arrow is at halfway of that distance. There will also be a time when it is halfway between the middle and end. There will be yet another moment it is halfway of the remaining $25 \mathrm{~cm}$. And so on.

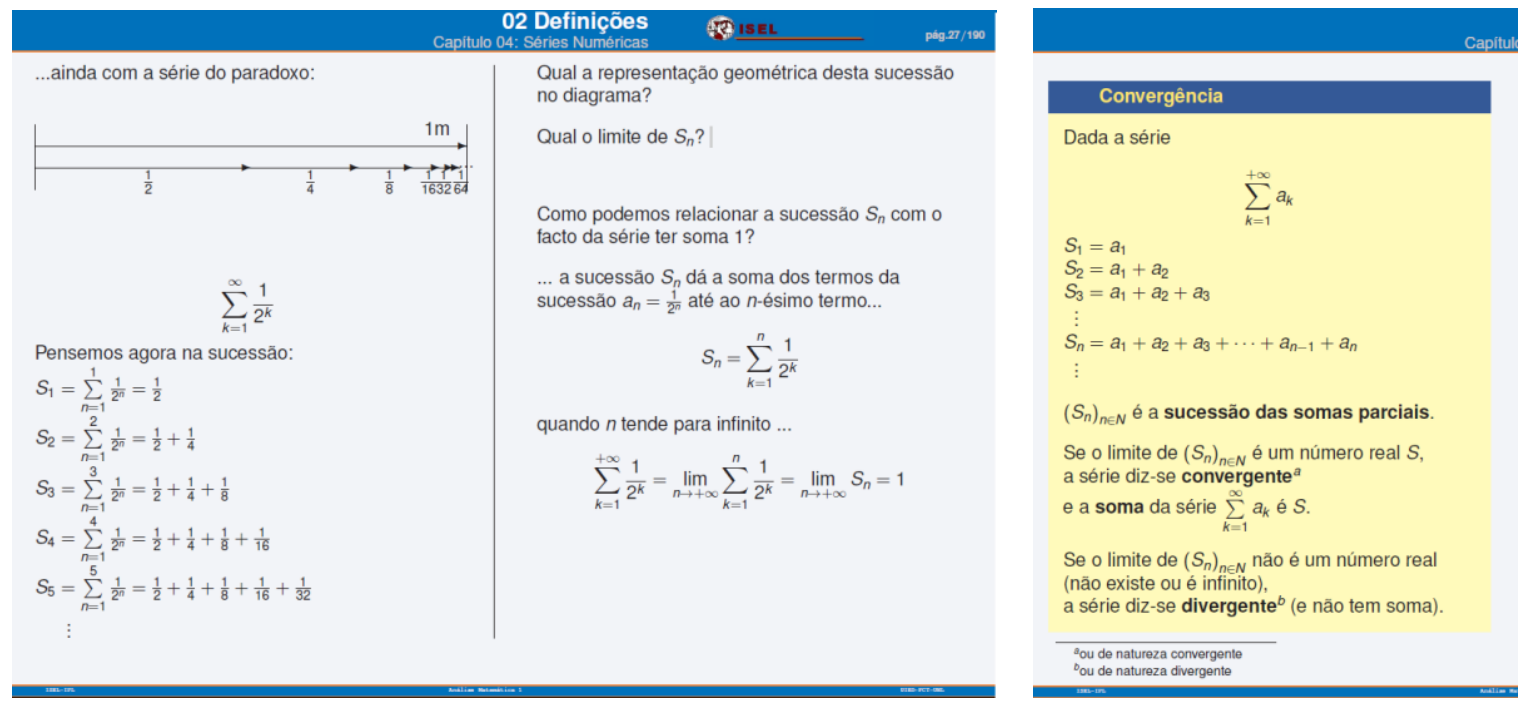

Figure 6. Definition of convergence of series (from reality to abstraction).

With this series, the intuitive notion of the meaning of the sequence of partial sums and the meaning of convergence of a series was explored. Only afterwards, these concepts are described formally and in an abstract way (Figure 6). With real cases everything is explored in a natural way. After a real case, the abstract definition becomes more tangible. It is easier to make connections with previous knowledge and get meaningful learning.

Proximal Development Zone. In the IDDs the exercises were constructed having in mind the Proximal Development Zone. The exercises were designed to enable the student to progress by himself from one exercise to the next, or at most, with the help of a teacher or a classmate. For example, in the IDDs, to teach how to calculate primitives it does not begin by asking one of the most difficult ones, it introduces functions more and more difficult to integrate. In the exercise of Figure 7 it is much more logical to make the point $\mathrm{k}$ ) after making j), and j) after having made i), than to begin by $\mathrm{k}$ ). The order in which exercises are presented is therefore crucial. 


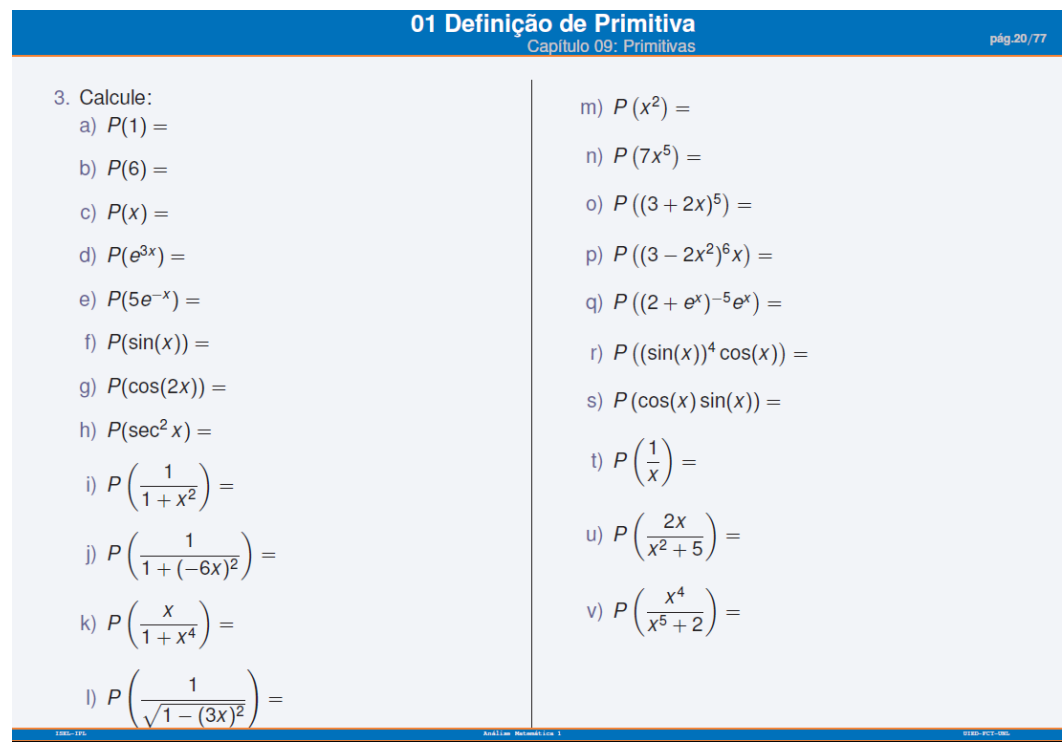

Figure 7. Exercises to introduce antiderivatives techniques.

Focus in One Objective Each Moment. In each moment, only one objective is focused and only that objective is explored. Just after the concept is understood, it may be mixed with other concepts in exercises, because it allows a student that missed a previous lesson or simply that did not manage a previous concept, to understand the new concept. For example, to teach that an antiderivative of a function like $u^{\alpha} u^{\prime}$ is $\frac{u^{\alpha+1}}{\alpha+1}$, there are not used unusual functions like hyperbolic sine or even tangents; on the contrary, familiar functions are used like polynomials and sine; otherwise students do not learn antiderivativing techniques simply because they do not know the derivative of unusual functions.

Another advantage of focusing on only one objective at a time is to save time. For example, when dealing with the calculation of extremes of a function, we begin by showing a specific problem (such as those of Figure 5), but only make all calculations to find their maximum (or minimum) for two or three of these exercises (enough for students to understand the method), then teach them to extract the function to maximize (or minimize) and not waste time on further calculations.

Multiple Representations. In IDDs there are abundant multiple representations of concepts, whenever it makes sense, not only the symbolic part of a concept but also the graphical, numerical and verbal parts are explored. The example of Figure 8 shows the concept of limit of sequences of quotients of polynomials when $n$ goes to $+\infty$. Here, beyond the usually explored symbolic representation, is explored its graphical, numerical and verbal representation.

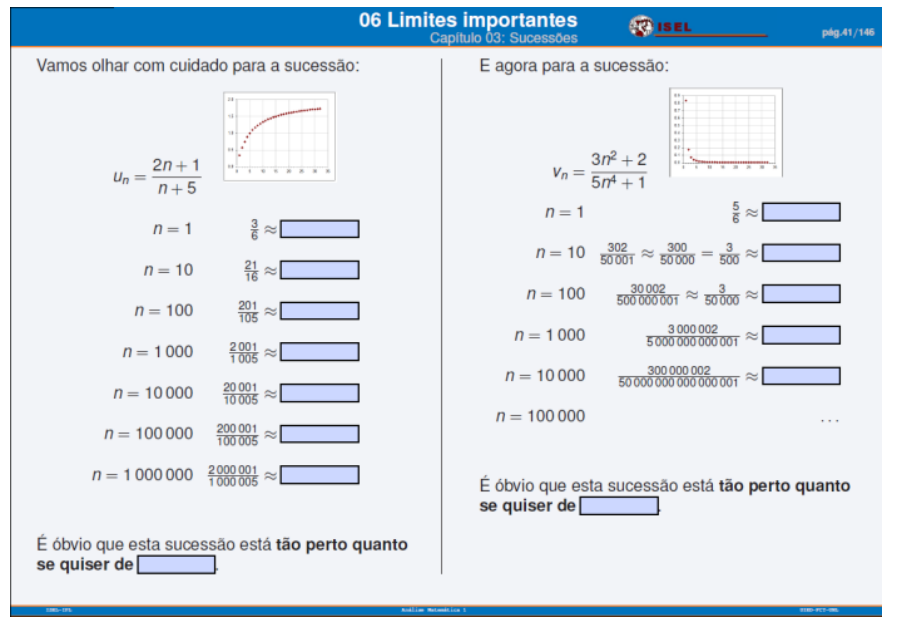

Figure 8. Calculation of the limit of sequences using multiple representations. 


\section{External support}

The IDDs require some external support: the use of software; the connection to links to some applets and tutorials on the Internet that may supply extra material and assessment of their performance; the IDDs are also connected with frequent quizzes in Moodle.

Using Software. The IDDs require the use of some software. A spreadsheet is required mainly to study sequences and functions to allow beyond of analytical, its numerical and graphical study. A Computer Algebra System (CAS) is required to make algebraic manipulation, to all kind of calculations like limits, extrema, antiderivatives, integrals, Taylor series, etc., and also to allow visualizations of graphics. The modelling system Modellus is required to model real life problems, to make animations and to mix multiple representations of a concept allowing understanding the connections between them. Figure 9 shows how it was possible to make a model, using a photo, with Modellus, of the front of a building of a Shopping Center in Lisbon.

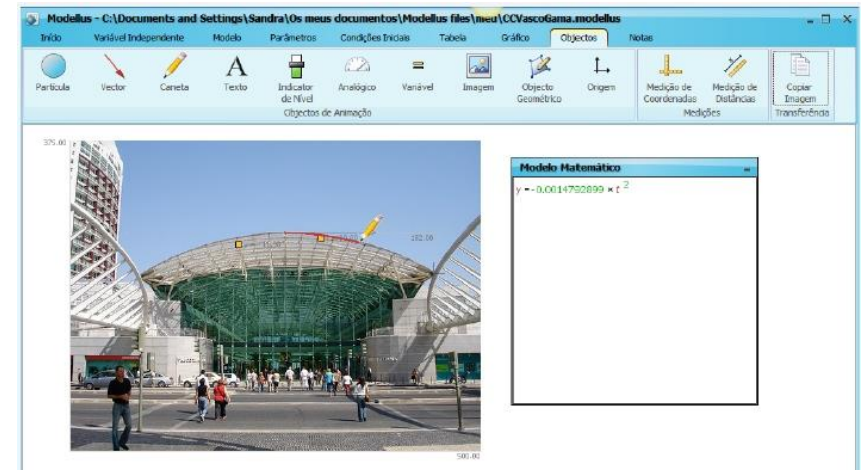

Figure 9. Modelling the front of Vasco da Gama Shopping Center using Modellus.

External Links. The IDDs external links for applets help students to visualize a concept. An example is http://www.math.psu.edu/dlittle/java/calculus/taylorseries.html. The IDDs also give links to pages of basic mathematics that are important prerequisites. In sites such as http://modulos.math.ist.utl.pt and http://cmup.fc.up.pt/cmup/apoiomat the students find theory, exercises and quizzes.

Quizzes on Moodle. The IDDs are complemented with frequent quizzes on Moodle with immediate feedback about the performance of the student. That feedback may be used by the student to see if he needs to study more or not, and by the teacher to find the subjects that students have more difficulties in and rearrange lessons to fight it.

\section{Format/Appearance}

The format and appearance were not neglected. It intends to be appellative, carefully structured, strongly organized and concentrated in one single document. Some advantages and some disadvantages came from the fact of the IDDs being digital.

All in One Document. The IDDs are complete in terms of theory and practice of the course. It has all subjects, introductions, motivations, all theory, lots of practice, bibliography, etc., in order to be the single document of the students: the book, the notebook, and the slides... all in one document. The fact that the theory and the questions are already written in the IDDs assures that students do not have to copy it to the notebook. This frees up time that may be fully spent thinking about the problem instead of being spent making a copy.

Appellative and Carefully Structured. Being appellative in interior and in front covers was also taken into account (see Figure 10). The IDDs are very carefully structured and organized. Each file has a navigation panel with the sections and subsections that makes fast to find a subject, and since it is digital it is also simple to search for a "word". 


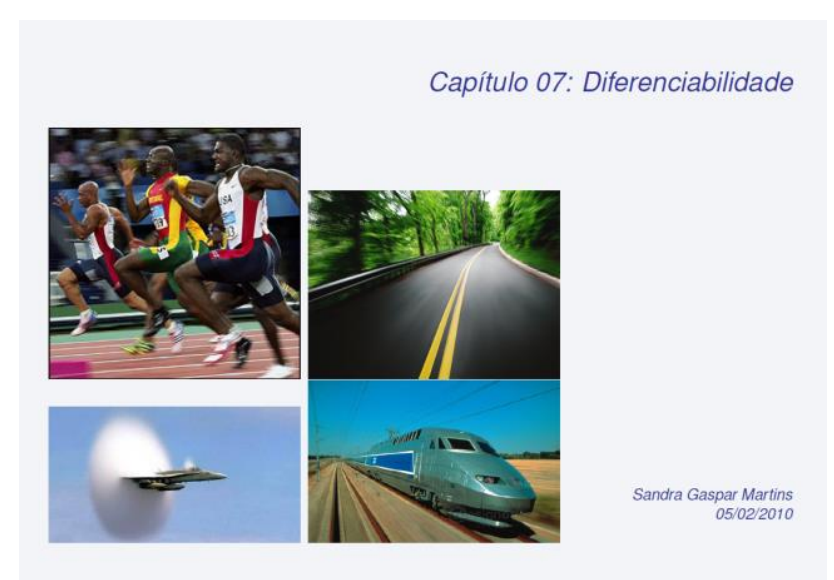

Figure 10. Front cover of Chapter 07- Differentiability.

Writing Math on a Computer. To make the IDDs become the notebook of students, since they cannot write text with mathematical symbols in Adobe Reader, they are required to use a mathematical text editor.

Since Mathtype was the most practical and was free for the students participating in the study, we chosen that program to be used during the study. The students wrote in Mathtype and then copied (in picture format) for the IDD. One problem happens when the student write a wrong answer and wants to fix it. To avoid writing it all again, it is suggested that the student keep the mathematical text file until the correction of questions. It is not very practical, but it was the least bad among the solutions found.

However, in an experimental class where the IDDs were tested, after two weeks of classes, already all, teacher and students, had given up solving the exercises in the IDDs. Curiously, the teacher was one of the first to give up (maybe because she was the most concerned with the lack of time to teach an extensive program or perhaps because she had many doubts about the effectiveness of this form of writing). The reason indicated by all is that it was not practical to write math in the IDDs, it requires much more time than writing by hand. While when writing by hand we only think about how to solve the exercise -writing by hand is natural, it happens automatically - when writing in the math editor we have to think about both things. We have to spend time thinking about how to write - even for people that type quickly. So, from then on, we used the combo boxes, the check boxes, etc., but we only used the text boxes if the answer did not require writing mathematical symbols. When this happened, students wrote, by hand, in the notebook.

The problem of writing mathematics did not happen only to us. According to Caprotti et al. (2007, p. 295) "this difficulty regarding expressing mathematical formulae in the virtual setting is probably the main obstacle slowing down the spread of e-education in the sciences".

Advantages and Disadvantages of the Format. The fact that the IDDs are in digital format instead of being in paper gives it some advantages and disadvantages. The digital option has the disadvantages of requiring students to possess their own laptop and always bring the laptop to class; moreover it is not (yet) very simple to write mathematical symbols on IDDs.

It is true that, with expertise, the IDDs could be made using sheets of paper photocopied or printed. For example, one activity that includes a Combo Box may be substituted in a sheet of paper by the same activity with the same options written on paper and the student chooses, as well, the meaningful option. The paper option would be, however, more expensive, less ecological and perhaps less attractive. 


\section{Study}

The DDIs were applied in an experimental class of 15 students and in the end students answered to an online questionnaire. Students indicate their level of agreement/disagreement with the following statements, in the scale 0-No Opinion, 1-Totally disagree,..., 4- Medium,..., 7- Totally agree.

- The material was well organized.

- It was easy to find a topic / formula in the PDFs.

- The standardization / uniformity of material was helpful.

- The fact that the material was very uniform disrupted the visual memory. This means: could you memorize the theorem $X$ that appeared on the right corner of that page? (As it happens when you write on paper ...).

- The initial experience of writing math on the computer it was practical and functional.

- I liked the way lessons were conducted.

- It seemed useful the fact of not spending time copying the theory (which was on the slides) and using it to solve exercises.

- It was important to see not only the analytical part of mathematics but also the graphical and numerical.

- It was interesting to see some applications of themes that were studied.

- The fact that the subject was shown interactively and not as a presentation was useful. For example, the teacher instead of saying that the properties are $A<B$ and $C>D$, asks students to fill with inequalities the relations between $\mathrm{A}$ and $\mathrm{B}$ and between $\mathrm{C}$ and $\mathrm{D}$.

The answers are shown in Table 1. From informal talks and from a Focus Group with these students, the researcher's perception was that students found the IDDs effective and useful.

Table 1. Number of students that have a certain level of agreement with the statements.

\begin{tabular}{|c|c|c|c|c|c|c|c|c|c|c|}
\hline & N.O. & Disagr. & & & Med. & & & Agree & & \\
\hline & 0 & & 2 & 3 & 4 & 5 & 6 & 7 & $N$ & Average \\
\hline Well organized & & & & & & 5 & 3 & 7 & 15 & 6.1 \\
\hline Easy to find a subject & & & & & & 3 & 7 & 5 & 15 & 6.1 \\
\hline Uniformity was helpful & & & & & 2 & 2 & 6 & 5 & 15 & 5.9 \\
\hline Bad for visual memory & & & 2 & 2 & 2 & 4 & 3 & & 13 & 4.3 \\
\hline Practical to write math & & & 2 & 2 & 6 & 1 & 3 & 1 & 15 & 4.9 \\
\hline Liked lessons & & & & & & & 9 & 6 & 15 & 6.4 \\
\hline Useful not copying theory & & & & & 1 & 2 & 5 & 7 & 15 & 6.2 \\
\hline Important Graphic/Numeric & & & & & 1 & 4 & 6 & 4 & 15 & 5.9 \\
\hline Interesting Applications & & & & & 2 & 3 & 7 & 3 & 15 & 5.7 \\
\hline Useful Interaction & & & & 1 & 3 & 5 & 6 & & 15 & 5.1 \\
\hline
\end{tabular}

\section{Conclusions}

The Interactive Digital Documents (DDIs) are files that enclose in one document all the material needed for the course (slides, book, notebook, exercises, etc.). They provide interactivity using ComboBoxes, CheckBoxes and TextFields. Those documents are owned by the student and are customized by him. They promote student-centred active learning in which the student evolves at his own pace. They are complemented with the use of software and Moodle quizzes. The approach to concepts emphasizes mathematics applications; start from real/concrete to the abstract viewpoints; explore multiple representations of concepts. The exercises are presented having in mind the proximal development zone of students.

The students of the experimental class that used the DDIs evaluated them positively. According to students, they are organized, it is easy to find a concept/formula, and it is useful their uniformity. Although, for some students, it may cause difficulties with visual memory. They identify another difficulty: writing math on a computer; it is not (yet) possible to write mathematical language fluently 
in a computer in order to think about the content that you are writing and not in the way of writing it, as when writing on paper.

The students reported that they enjoyed the course where the DDIs were used; considered useful not having to copy the theory and exercises from the blackboard; considered interesting to see the graphical and numerical approach to the concepts and the applications of concepts; and considered useful the interaction provided by the DDIs.

\section{Note}

The IDDs, its source code in LaTeX, and the Moodle quizzes are available in http://sandragasparmartins.wordpress.com. The IDDs are part of a PhD thesis available in http:/ / hdl.handle.net/10362/9675.

\section{References}

Anderson, R. D. \& Loftsgaarden, D. O. (1987). A special calculus survey: Preliminary report. In L. A. Steen (Ed.), Calculus for a new century (pp. 215-216). Washington, DC: The Mathematical Association of America.

Artigue, M. (2011). Theories of mathematics education: seeking new frontiers (Advances in Mathematics Education). Research in Mathematics Education, 13(3), 311-316.

Beichner, R. J. (2008). The SCALE-UP Project: A Student-Centered Active Learning Environment for Undergraduate Programs. Paper presented at the BOSE Conference on Promising Practices-Innovation in Undergraduate STEM Education, Washington, DC.

Blackwell, L. S., Trzesniewski, K. H., and Dweck, C. S. (2007). Implicit Theories of Intelligence Predict Achievement Across an Adolescent Transition: A Longitudinal Study and an Intervention. Child Development, 78(1), 246-263.

Caprotti, O., Seppala, M., \& Xambó, S. (2007). Novel Aspects of the Use of ICT in Mathematics Education. In M. Iskander (Ed.), Innovations in E-learning, Instruction Technology, Assessment, and Engineering Education (pp. 295-299). Springer Netherlands.

Chickering, A. W., \& Gameson, Z. F. (1987). Seven Principles for good practice. A. A. H. E. Bulletin, 39, 3-7.

Crouch, C. H., \& Mazur, E. (2001). Peer Instruction: Ten years of experience and results. American Journal of Physics, 69(9), 970977.

Dori, Y. J., \& Belcher, J. (2004). Improving student's understanding of electomagnetism throught visualizations- A large scale study. Paper presented at the 2004 NARST-Annual meeting- National Association for Research in Science Teaching Conference, Vancouver, 1-7.

Kaput, J. J. (1994). The representational roles of technology in connecting mathematics with authentic experience. In R. Biehler, R. W. Scholz, R. Sträßer \& B. Winkelmann (Eds.), Didactics of Mathematics as a Scientific Discipline (pp. 379-397). Dordrecht: Kluwer Academic Publishers.

Machado, E. (2006). Os computadores na facilitação da aprendizagem: estudo tomando o conceito de função. PhD, Universidade do Minho.

NCTM. (2000). Principles and standards for school mathematics, Reston, VA.

Tall, D. O. (1993). Students Difficulties in Calculus. Paper presented at the ICME-7, Québec, Canada, 1-15.

Teodoro, V. D. (2002). Modellus: Learning Physics with Mathematical Modelling PhD, Universidade Nova de Lisboa, Lisboa.

Zerr, R. J. (2010). Promoting Students' Ability to Think Conceptually in Calculus. PRIMUS, 20(1), 1-20. 